\title{
A Corpus-based Discourse Information Analysis of Chinese EFL Learners' Autonomy in Legal Case Brief Writing
}

\author{
Jinshi Chen ${ }^{1}$ \\ ${ }^{1}$ School of English and Education, Guangdong University of Foreign Studies, Guangzhou, China \\ Correspondence: Jinshi Chen, School of English and Education, Guangdong University of Foreign Studies, \\ Guangzhou, China. Tel: 86-159-8918-7299. E-mail: jinshichen@126.com
}

Received: February 14, 2017 Accepted: March 22, 2017 Online Published: March 24, 2017

doi: $10.5539 /$ elt.v10n4p150 URL: http://doi.org/10.5539/elt.v10n4p150

\begin{abstract}
Legal case brief writing is pedagogically important yet insufficiently discussed for Chinese EFL learners majoring in law. Based on process genre approach and discourse information theory (DIT), the present study designs a corpus-based analytical model for Chinese EFL learners' autonomy in legal case brief writing and explores the process of case brief formation. The results show that in the stages of writing and self-assessment, learners can make full use of the corpus to obtain information, complete macro-information and micro-information output, and self-assess the specific legal register. The findings indicate that the realization of global coherence and local coherence in case briefs depends on discourse information output with appropriate language use. It is hoped that the study will help Chinese EFL learners build information awareness in legal writing and promote their language output and autonomous learning.
\end{abstract}

Keywords: Chinese EFL learners, autonomous learning, case brief, discourse information analysis

\section{Introduction}

In the process of internationalized talent cultivation and personnel training, more and more colleges and universities in Mainland China have opened the course Legal English for the majors in law, diplomacy, international trade, international finance, international politics and so on (Miao, 2014). Case brief writing is an important content in legal English course, and case briefs are short statements summarizing case judgments or opinions, i.e. written legal reports after the application of relevant laws and regulations to analyze specific legal cases, including relevant facts, issues, holding and court's reasoning (Brumbaugh, 1917; Candlin et al., 2002; Garner, 2004). In such common-law countries as UK and the United States, law students are often required to present case briefs for group discussion or debate in the course of their studies (Krois-Lindner \& TransLegal, 2006), so in legal education analyzing and discussing legal cases in class is also an important pedagogical technique used and students must therefore learn how to accurately read, analyze, and brief cases (Candlin et al., 2002).

As a legal genre, however, case briefs are entirely different from ordinary narratives (Bhatia, 2013). In case brief writing much emphasis is laid on learners' thinking process for the final decisions, in which reasoning process should be logical and persuasive, and legal points or arguments should be proved directly with evidence and opinions (Brumbaugh, 1917; LeClercq, 1995). Case briefs boast highly conventionalized, stylized forms with specifically logical, fairly stable and consistent genre features (Candlin et al., 2002; Clarence et al., 2014), which can be embodied by words, sentences and discourse in language use and communication (Wang, 2003; Wang \& Zhao, 2009), and case briefs have a typical genre structure, including identification of the case, description of the facts of the case, arguments of the judge and the pronouncement of judgment (Bhatia, 2013).

The teaching of English for Legal Purposes, whether academic or occupational, has always been guided by pedagogical convenience rather than effectiveness (Bhatia, 2013). Fortunately, a genre-based language curriculum will be flexible to facilitate case briefs teaching and allow much freedom to the participants in their teaching and learning process (Bhatia, 2013), which has also been adopted in legal English teaching practice in Mainland China.

In legal English teaching and learning in Mainland China, case analysis is also an effective approach, through which learners will be cultivated to improve their ability of analyzing and solving legal problems and their 
performance in legal practice (Wu, 2010; Huang \& Xia, 2010). However, in the universities nowadays, teachers are bearing heavy psychological burden of legal English in that both the credits and credit hours of legal English are quite limited, resulting in their teaching far from legal practice (Huang \& Xia, 2010; Miao, 2014; Chang, 2015). Thus, there is such a great need of strengthening learners' case brief writing skills and autonomous learning ability. Learners need to master the methods to construct the textual structures of case briefs at both macro-level and micro-level.

Even though the structures of case briefs have been explored in the field of discourse analysis, e.g. a typical four-move structure (Bhatia, 2013), and an organizational strategy or an art of persuasive writing has also been provided for legal cases throughout classes and learner's law school career (Crane, 2010; McElhaney, 1996), insufficient studies focus on and few approaches are employed for the writing process teaching and learners' autonomy in case brief writing. In terms of output-driven hypothesis (Wen, 2008, 2013) in English as a Foreign Language (EFL) learning environment, learners will be helped to develop their English pragmatic competence in the field of legal profession through their correct understanding of specific cases and accurate expression to complete a case brief. As an important research achievement of writing teaching in the post-method era, process genre model (Badger \& White, 2000), synthesizing product approach (Pincas, 1982a, 1982b), process approach (Hedge, 1993; White \& Arndt, 1991) and genre approach (Flowerdew, 1993; Bhatia, 2013), has offered a possible way for learners' case brief writing.

In accordance with process genre model (see Figure 1) (Badger \& White, 2000), writing is regarded as a discourse formation process, in which teachers can make language knowledge and writing skills available to assist learners to finish writing when necessary. Great importance is attached to the writing itself and writing ability development. The writing involves knowledge about language, knowledge of the context and skills in using language while writing ability is developed by exploring learners' language output potential and offering necessary input to learners. From the genre perspective, specific social situation determines writing purpose and register features (i.e. field, tenor and mode). The language use in specific discourse covers concrete content of writing object and corresponding language knowledge. Writers need to use such language means appropriate to the genre as vocabulary, grammar and discourse structure to plan, draft, proofread, revise and publish their works.

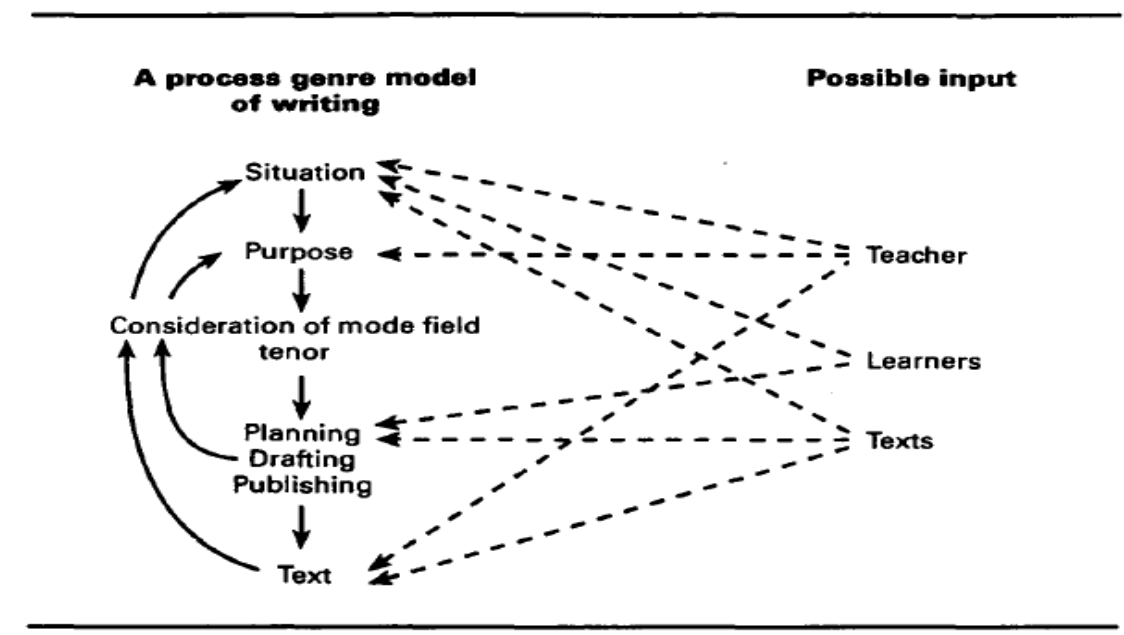

Figure 1. A genre process model of teaching writing

In the process genre approach, situation, information input such as language knowledge or writing skills comes from teachers, other learners, examples of target genre or some corpus related to the target genre (Badger \& White, 2000). Currently, corpus-based teaching and research have fruitful achievements in the field of genre writing (Friginal, 2013; Hong \& Cao, 2014), so corpus resource can be utilized fully to provide learners with much information and serve learners' autonomy in writing.

From the perspective of discourse information, a few studies have been made on Chinese students' English writing or their self-assessment for legal English writing. From such output aspect, students' language use in their compositions for the coherent information output has been analyzed with the tree model (Du, 2009). 
Meanwhile, based on output-driven hypothesis (Wen, 2008, 2013), an analytical framework has been designed for self-assessment for legal English writing, and the results show that the importance of information hierarchical structure for global coherence and information knot distribution and information element output for local coherence (Chen, 2015). Although the former study has touched advanced English writing and the latter has focused on students' self-assessment for legal writing, discourse information output in brief writing has actually not been explored adequately for autonomous learning till now. Thus, these studies have made direct reference available for case brief writing and research.

Based on the literatures reviewed above, the present paper constructs a corpus-based framework for discourse information analysis of students' autonomy in case brief writing to explore how learners write legal case briefs autonomously. Through data analysis and discussion, the following three research questions will be answered:

1) How do EFL learners implement their case brief writing autonomously through discourse information processing?

2) How do EFL learners assess their case brief writing autonomously through discourse information processing?

3) In the writing process, how do EFL learners realize discourse information processing by means of language use?

\section{Theoretical Framework}

\subsection{Discourse Information Theory}

\subsubsection{Tree Information Structure and Information Units}

Discourse information theory (DIT) (Du, 2007, 2014) suggests that the information in a discourse is woven into a network which is a hierarchical tree structure and the system has a kernel proposition $(\mathrm{KN})$ surrounded by all information units at different levels (see Figure 2). Discourse information structure is composed of information units each of which acts as a meaningful unit based on a proposition. Information units relate to each other and each develops its superordinate information unit from a certain aspect.

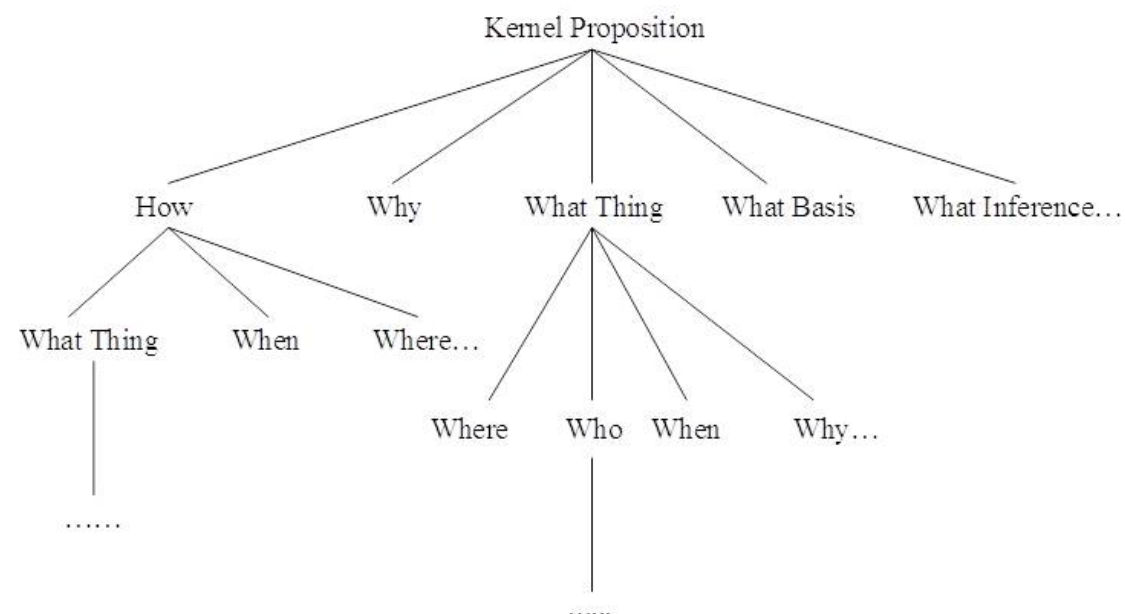

Figure 2. Tree structure of discourse information (from Du, 2007)

\subsubsection{Information Knots and Information Levels}

Based on the application of DIT in legal discourse studies (see Du, 2007, 2014; Ge, 2014; Guan, 2015), information units are represented by key words, which can be used to analyze the specific content in a legal discourse. There are hierarchical relations between information units, i.e. the information units at the lower levels can be developed to those at the higher levels (see Figure 2). Those relations are called information knots, labelled by $15 \mathrm{Wh}$ - phrases (Du, 2007), for example, WT (what), WN (when), WF (what fact), WY (why) and so on (see Table 1), which denote from what aspect subordinate information units specify their superordinate ones in a discourse, such as thing, time, fact, reason... 
Table 1. Types of information knots (from Du, 2007)

\begin{tabular}{llll}
\hline $\boldsymbol{W H}$-phrases & Labels & $\boldsymbol{W H}$-phrases & Labels \\
\hline What Thing & WT & How & HW \\
What Basis & WB & Why & WY \\
What Fact & WF & What Effect & WE \\
What Inference & WI & What Condition & WC \\
What Disposal & WP & What Attitude & WA \\
Who & WO & What Change & WG \\
When & WN & What Judgment & WJ \\
Where & WR & & \\
\hline
\end{tabular}

In each discourse, the kernel proposition and its subordinate information units can be identified, which correspond to information knots and level codes in the tree diagram (see Figure 3).

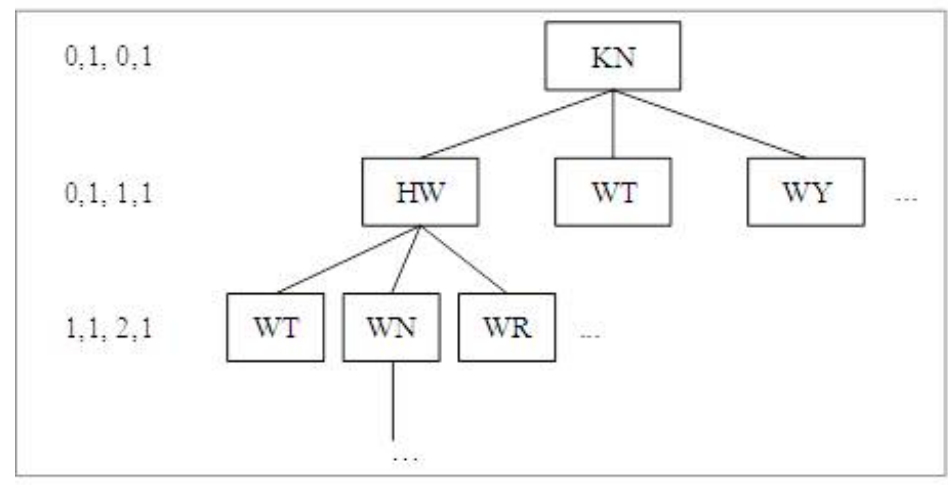

Figure 3. Discourse information levels

Level codes are composed of level number and position number of the information unit and its superordinate one. In Figure 3, KN is the information focus of the whole discourse. It is at the top of the tree structure, so it has been endowed with the level code ' $0,1,0,1$ '. It is developed into subordinate information knots HW, WT and WY at the first lower level in this figure. Their level codes are ' $0,1,1,1$ ', ' $0,1,1,2$ ' and ' $0,1,1,3$ ' respectively. Knot HW has its own subordinate knots WT, WN and WR, the level codes of which are '1,1,2,1', '1,1,2,2' and ' $1,1,2,3$ '. '1,1,2,3' means Knot WR takes up the third position (tagged as 3) at level 2. It is subordinate to Knot HW which is at the first position (tagged as 1) at level 1.

\subsubsection{Information Sharing Categories}

Information sharing categories reflect the degree to which participants in the communication share the information. The richer information the participants share, the less details they need to provide in the communication. In DIT, there are six types of sharing categories (see Table 2), including A-events (Known to A, but not B), B-events (Known to B, but not A), C-events (Known to both A and B), E-events (Known to neither), O-events (Known to everyone) and D-events (Known to be disputable). 
Table 2. Information sharing categories (Du, 2013: 183)

\begin{tabular}{lll}
\hline Context & Sharing Categories & Notes \\
\hline monologue & $\mathrm{A}, \mathrm{B}, \mathrm{C}, \mathrm{E}, \mathrm{O}, \mathrm{D}$ & $\mathrm{C}=\mathrm{AB}, \mathrm{E}=\mathrm{BA}$ (known to neither) \\
question & $\mathrm{a}, \mathrm{b}, \mathrm{c}, \mathrm{e}, \mathrm{o}, \mathrm{d}$ & Corresponding to the ones in monologue \\
dialogue & $\mathrm{R}, \mathrm{S}, \mathrm{T}, \mathrm{Y}, \mathrm{Z}, \mathrm{U}$ & Corresponding to the ones in monologue \\
\hline
\end{tabular}

The analysis of sharing categories, together with concrete legal context, conduce to the study of legal discourse from the cognitive and social aspects in that particular shared knowledge of participants forms the basic mechanism of requests, rejections and even rules.

\subsubsection{Information Elements}

In addition, at the micro level, each information unit consists of information elements. There are three main types of information elements, Process, Entity and Condition (Du, 2014). Every type has its sub-types, see Table 3.

Table 3. Types of information elements (Du, 2014: 142)

\begin{tabular}{llllll}
\hline Type & Labels & Type & Labels & Type & Labels \\
Process & P & Entity & e & Condition & c \\
\hline State & S & agent & 1 & instrument & $\mathrm{i}$ \\
Quality & Q & dative & 2 & location & 1 \\
Appear & A & patient & 3 & source & $\mathrm{s}$ \\
Relation & $\mathrm{R}$ & factitive & 4 & goal & $\mathrm{g}$ \\
Behavior & $\mathrm{B}$ & attribute & 5 & comitative & $\mathrm{c}$ \\
Cause & $\mathrm{C}$ & & time & $\mathrm{t}$ \\
Turn & $\mathrm{T}$ & & affected & $\mathrm{a}$ \\
Negation & $\mathrm{N}$ & & with & $\mathrm{w}$ \\
& & & situation & $\mathrm{o}$ \\
& & & basis & $\mathrm{b}$ \\
& & & & manner & $\mathrm{m}$ \\
\hline
\end{tabular}

Since discourse information analysis at both macro and micro levels applies to information-centered writing teaching and evaluation ( $\mathrm{Du}, 2009)$, it is appropriate to explore the issues existing in the process of teaching English writing based on DIT. This is consistent with the teaching design principle of process genre approach, namely both information input and information output start from the contexts and macrostructures in certain genres, go deep into the micro level, and complete the writing through linguistic means, thus cultivating learners' autonomous establishment of information consciousness and genre consciousness in the writing process, and enhancing their writing competence.

\subsection{Analytical Framework}

To achieve the research objectives, answer the research questions, and implement process genre approach in legal case brief writing, the following analytical framework for learners' autonomy in case brief writing has been constructed based on the integration of discourse information analysis and linguistic analysis (see Figure 4). 


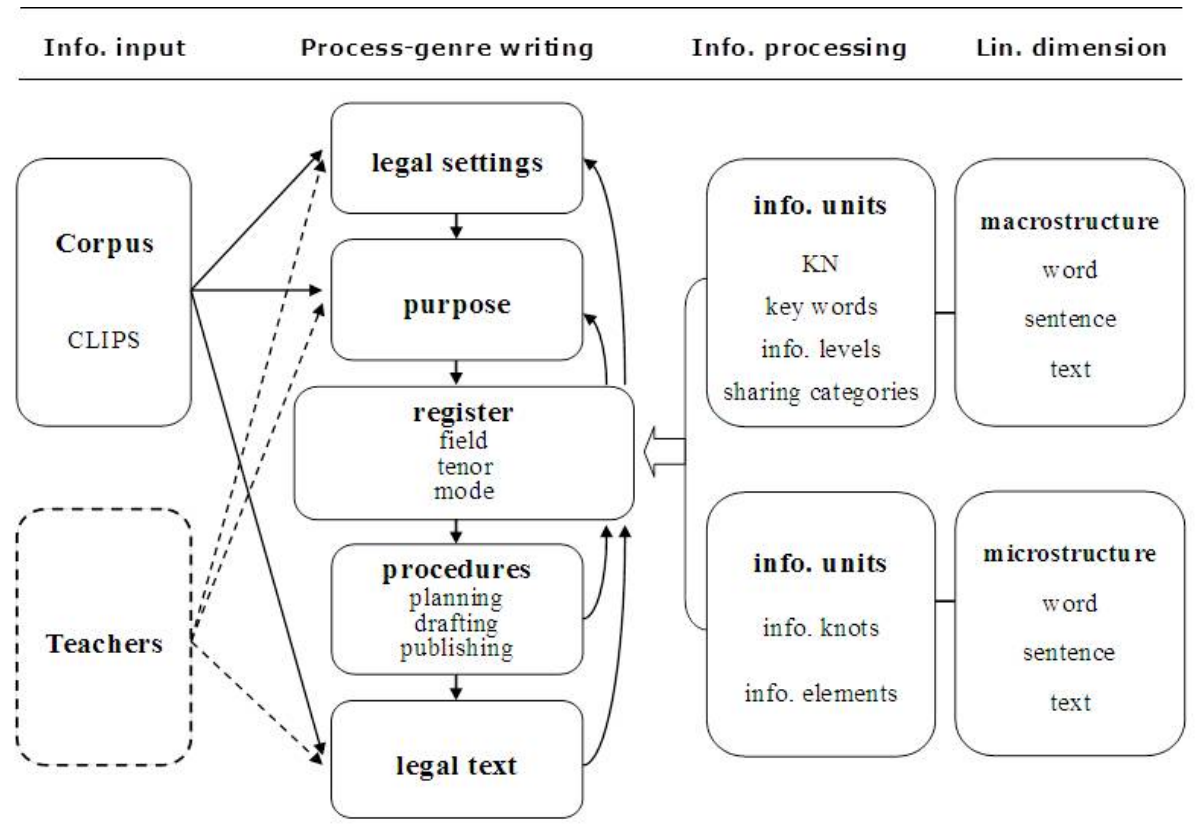

Figure 4. Analytical framework for learners' autonomy in case brief writing (Info.: information; Lin.: linguistic)

According to process genre approach, writing process, starting from legal situations and ending with legal discourse, consists of several circulating stages, i.e. legal settings, purpose, register, writing procedures and legal text. In autonomous learning circumstances (see Figure 4), corpus-based examples, background knowledge and information input of specific cases are necessary before writing (solid arrows in Figure 4), information input from teachers is optional (dotted arrows in Figure 4). Then students design their writing in accordance with the specific register, draft case briefs (including the assessment and the revision of the briefs by themselves), and finish the final versions for submission.

Specifically, in the stages of information input, draft design, drafting and final manuscript, information processing is always done through language, genre features are reflected and differentiated by the variables of register, serving discourse contexts and writing purposes (Biber \& Conrad, 2009; Bowles, 2012; Moessner, 2001). Both the legal brief writing and students' self-assessment for their writing will be analyzed from the aspect of information processing, i.e. information units, kernel proposition, key words, information levels and sharing categories will be analyzed to explore how the macro information is processed while information units, information knots and information elements will be analyzed to investigate how the micro information is processed through such language output as words, sentences and texts.

\subsection{Material and Methodology}

In the light of the above-formulated framework, two models of case briefs and ten learners' works used for the analysis and discussion will be extracted from 'Corpus for the Legal Information Processing System' (CLIPS), which has been built based on DIT for forensic linguistic studies and legal language teaching and learning. Model No. 01 is, the summary of a brief for the case 'ProCD. Inc. v. Zeidenberg and Silken Mountain Web Services' (Krois-Lindner \& TransLegal, 2006: 271-272), used for the information input before learners' autonomy in writing, and Model No. 02 is the one consistent with the case and the requirements for learners' practice, used by learners as a reference for their self-assessment. The other ten manuscripts of different qualities extracted from CLIPS are completed by ten law school students as Chinese EFL learners in a university. According to the course requirements, the students should write a case brief in 300 words or so after learning 'Uniform Commercial Code' (UCC) and reading the case 'Data Processing Services, Inc. (DPS) v. L. H. Smith Oil Corp.' (Court of Appeals of Indiana, 1986). Through the data analysis, it will be discussed how process genre approach is applied for Chinese EFL learners' autonomy in case brief writing. 


\section{Data Analysis}

\subsection{Discourse Information Processing for Learners' Autonomy in Case Brief Writing}

\subsubsection{Information Input before Writing}

Information input is the starting point of process genre approach for writing, and also the process of learners' knowledge accumulation before writing. Besides the information of case briefs provided by teachers optionally or learners' previous knowledge of legal English, learners can obtain the data from CLIPS for their understanding of the case, and complete the information input before writing.

The works of case briefs require distinct genre, brief introduction, concise reasoning, clear hierarchy and logical structures (Gersten, 2007; Pyle \& Killoran, 1999; Li, 2008). For example, CLIPS offers learners the macro tree structure of Model No. 01 (see Figure 5), visually demonstrating the information at different levels, and provides them with key words $<$ case brief $>$, <legal facts $>$, <legal issue $>$, <holdings $>$ and $<$ reasoning $>$, presenting such five main parts in case brief writing as title, legal facts, legal issues, court decision and legal reasoning (Krois-Lindner \& TransLegal, 2006). Meanwhile, Figure 5 has shown that legal facts and legal reasoning are rich in content and the greatest in length, containing a number of information units at lower levels. All these conform to the genre features of case briefs. Model No. 01 also provides the learners with the micro information of this genre, showing the communicative purpose of case briefs in the legal context.

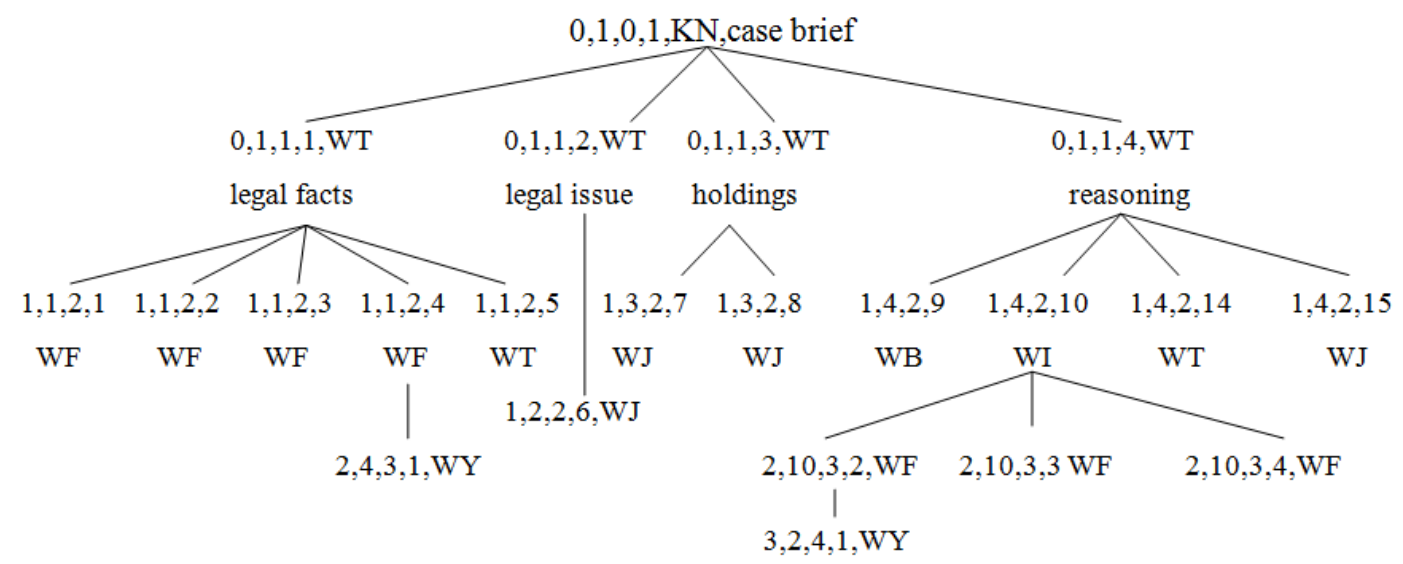

Figure 5. Macro structure of Model No. 01

Information input also includes reading the text of the new case 'Data Processing Services, Inc. (DPS) v. L. H. Smith Oil Corp.'. After fast reading, learners can catch the macro structure of the text (Maciel et al., 1983), while through intensive reading to absorb new information, they will be able to get the micro structure (Crane, 2010). After sufficiently understanding the construction and organization of the legal text grounded on genre analysis (Ren \& Ding, 2012), learners will commence their writing from the restructuring of the macro information to the design of the case brief outline.

\subsubsection{Macro Discourse Information Processing}

In learners' case brief writing, an outline will be designed through macro information processing. First, with reference to model briefs and idiomatic structures, the key words in such five parts as title, legal facts, legal issues, holdings and legal reasoning can be listed, among which title, legal issues and holdings can be completed while outline design is being done in that the three parts with fixed structures require fewer information units. For example,

(1) a. $<$ KN $>$ ProCO Inc. v. Zeidernberg and Silken Mountain Web Services

86 F.3d 1447 (7th Cir., 1996)

b. $<\mathrm{KN}>$ Data Processing Services, Inc. v. L. H. Smith Oil Corp.

In Example (1), 'a' and 'b' are the kernel propositions (KN) of Model No. 01 and a student's brief respectively, which reflects the legal situations and register features. The formulaic expression 'A (plaintiff) v. B (defendant)' 
has been used, and the ruling date and the case number can be listed and centered under the expression 'A (plaintiff) v. B (defendant)' like Example (1)a if they are given in the original text of the case.

In the process of outline design, the relations between sharing categories and the tenor of the brief should be taken into consideration for the confirmation of subjective and objective tenors in writing. For example, the legal issue of Model No. 01 is ' $\angle \mathrm{A}>$ Whether a shrink-wrap license constitutes an enforceable sales contract.', in which the sharing category ' $\angle \mathrm{A}>$ ' has been used. This is the learner's subjective question after his/her analysis of the original text of the case 'ProCO Inc. v. Zeidernberg and Silken Mountain Web Services' and the expression 'whether....' is a traditional structure conforming to the legal genre. The legal facts are all labeled as the sharing category ' $<\mathrm{O}>$ ', which have laid the foundation for the above-mentioned legal issue 'whether....' in that the legal facts have provided readers with such known information involved in the case as time, place, parties, things and so on. In the part of legal reasoning, the majority of fact units are also the sharing category ' $<\mathrm{O}>$ ', which serve readers' inferences and judgments. The court holding is the answer to the question 'whether....', with a 'yes or no' structure and a statement also tagged as the categories ' $<\mathrm{O}>$ ', i.e. ' $<\mathrm{O}>\mathrm{Yes}$. $<\mathrm{O}>$ The court held that the shrink-wrap license is valid and enforceable as a sales contract.' Since the category ' $<\mathrm{O}>$ ' means that the information can be shared to the highest degree ( $\mathrm{Du}, 2007)$ by the learner, all the readers, and all the parties involved in the case, the objective language used as the carrier has guaranteed the good acceptance of the information transmitted in the three parts of the case brief.

Meanwhile, from the aspects of information units and information levels, and with the macro structure in Figure 5 for reference, the whole text of the new case 'Data Processing Services, Inc. v. L. H. Smith Oil Corp.' will be analyzed for the identification of the KN, the information units at Level 1 and their subordinate ones. Then a discourse tree diagram can be constructed and the key words in each information unit can be tagged by the students for their writing preparation.

While writing a case brief, the macro information will be processed firstly, including the number of information units, the distribution of sharing categories and the hierarchy of information levels. The statistical analysis shows that seven of the ten briefs are similar to Model No. 02, i.e. with reasonable number of information units (30 or so) and appropriate length ( 300 words or so). Each of the seven briefs has one and only one ' $<\mathrm{KN}>$ ', revealing the main idea $(\mathrm{Du}, 2007)$ in the seven independent texts. However, some structural differences between these briefs can be evidenced by the legal reasoning.

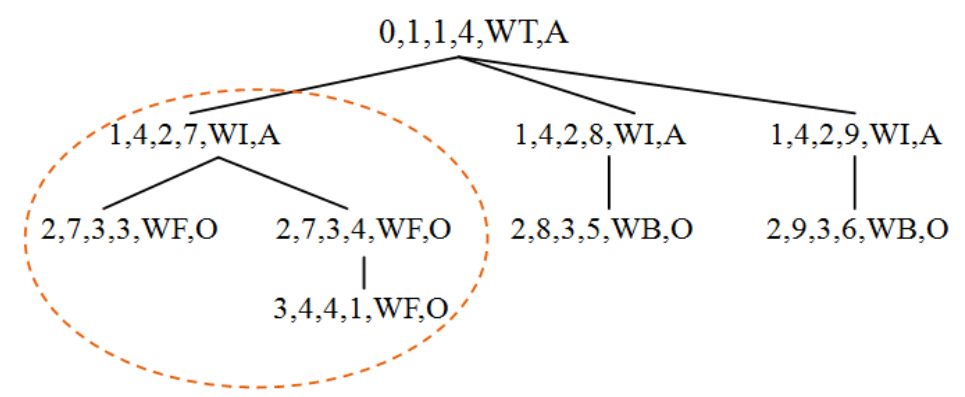

Figure 6. Information structure of reasoning in Model No. 02

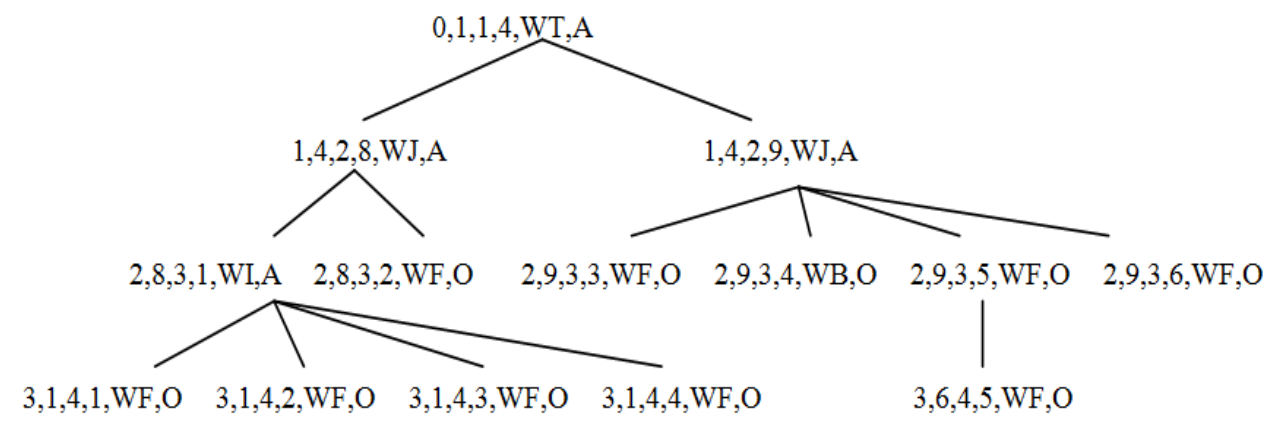

Figure 7. Information structure of reasoning in Brief No. 04 
In the legal reasoning of Model No. 02 and Brief No. 04 (see Figures 6 and 7), many information units of legal facts ' $\angle \mathrm{WF}>$ ' and legal basis ' $\angle \mathrm{WB}>$ ' play the subordinate roles through the objective highly-shared category ' $<\mathrm{O}>$ ', which serve their superordinates (i.e. legal inferences ' $<\mathrm{WI}>$ ' and legal judgments ' $<\mathrm{WJ}>$ ') through the subjective category ' $<\mathrm{A}>$ '. In Model No. 02 (see the dotted circle in Figure 6), three information units ' $<2,7,3,3>$, $<2,7,3,4>$ ' at Level 3 and ' $<3,4,4,1>$ ' at Level 4 , with the highly-shared category ' $<\mathrm{O}>$ ', support their superordinate ' $<1,4,2,7>$ ' and advance the information development from lower levels to higher ones. This type of logical reasoning in legal settings has been made from objective facts to subjective inference, and its persuasiveness is conducive to the answers to and the justification for the legal issue.

\subsubsection{Micro Discourse Information Processing}

\subsubsection{Information Knots and Micro Structure}

Through the analysis of information knots, it will be investigated how the logical relations between information units are constructed, whether each information knot serves its superordinate information and whether all the parts of the brief are unified organically and progressively. The hierarchical relations between information units are embodied by information knots and the distribution of information knots is an important means for micro discourse information processing in legal texts ( $\mathrm{Du}, 2007)$. Statistically (see Figure 8), 283 information knots in the ten briefs consist of 171 WFs (accounting for $60.4 \%$ of all), 31 WTs (11\%), 30 WJs (10.6\%), 24 WIs (8.5\%); the other seven types WC, WP, WN, WB, WY, WO and WA amount to 27 , taking only up $9.5 \%$ of all.

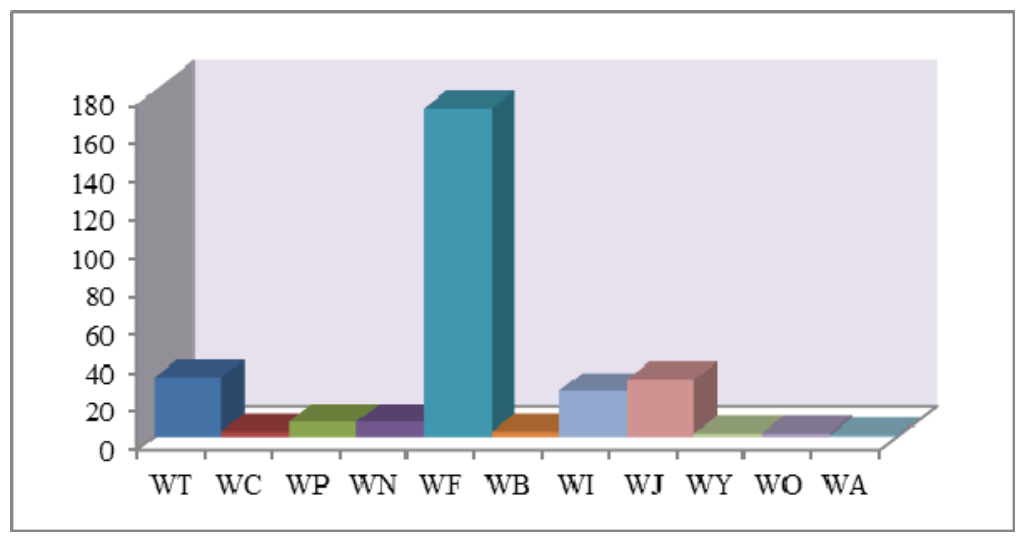

Figure 8. Distribution of information knots in students' case briefs

In accordance with textual features of legal genre, information knots ' $<\mathrm{WB}>$ ' and ' $<\mathrm{WF}>$ ' embody the universal principles for the solutions to conflicts based on laws and facts in legal practice ( $\mathrm{Du}, 2007)$ and make decisive contribution to local coherence in legal facts and legal reasoning. Undoubtedly, the information ' $<\mathrm{WF}>$ ', always transmitted to state legal facts, plays a crucial role in the part of legal reasoning. Learners usually need to

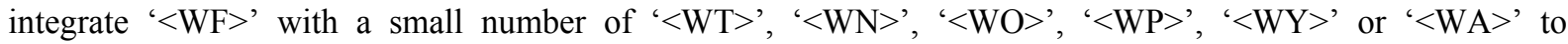
introduce the case and the first instance briefly to readers. Therefore, in case briefs the WFs are of much larger quantity and distributed in a much more extensive way. In the part of legal reasoning, the information knot ' $<\mathrm{WF}>$ ' is utilized to support superordinate units, or combined with the information knot ' $<\mathrm{WB}>$ ' or other knots to lay the foundations for legal inferences or legal judgments. Accordingly, the relational structures 'WF-WI' (fact-inference) or 'WF-WJ'(fact-judgment) have been formulated, which guarantee the reasonable structures and rigorous logic in legal reasoning.

\subsubsection{Information Elements and Cohesion}

In case brief writing, information elements at the micro level should also be taken into consideration, which can help realize the language use for logical structures. Process centers on predicate, so the Quality and the Behavior of legal facts will be realized through the use of predicate; the parties in legal cases will be reflected by such entities of information elements as agent and dative in process; various types of Process in specific conditions will be achieved by the information of time, locations and so on (Pan \& Du, 2011). For example,

(2) $<2,7,3,3, \mathrm{WF}>$ In this case, Smith bargained[B] for DPS's skill in developing a system to meet its specific needs. $<3,4,4,1, \mathrm{WF}>$ Although the end result was $[\mathrm{R}]$ to be preserved by means of some physical manifestation 
such as hardware, $<2,7,3,4, \mathrm{WF}>$ it was DPS's knowledge, skill and ability for which Smith bargained.

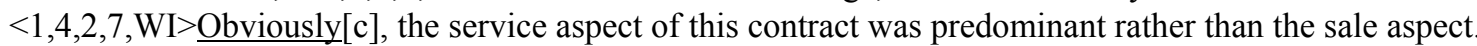

Example (2) is partial information of the reasoning in Figure 6. The first three units are represented with one simple sentence 'In this case, Smith bargained...' to express behavior, and one complex sentence with a subordinate clause 'Although the end result..., it was...' to convey the concessive relation. 'bargained' and 'was' are two different types of Process, 'behavior [B]' and 'relation [R]', which offer legal facts ' $<\mathrm{WF}>$ ' to readers; on the basis of the previous three WFs, the element 'comitative [c]' (obviously) is used as a cohesive device and for the subjective inference ' $\angle \mathrm{WI}>$ '. These information elements are employed for constructing the relation 'WF-WI' between subjective information units and objective one, which has promoted the information development effectively.

(3) $<\mathbf{1 , 1 , 2 , 1}>\underline{\text { Smith }}[\mathbf{1}]$ orally contracted [B] DPS[3] for a development of the computer software[2] for his IBM System-32 computer. $<\mathbf{1 , 1 , 2 , 2}>$ Later[t], DPS was engaged to develop and implement [B] a data processing system for Smith's new IBM System-34 computer. $<\mathbf{1 , 1 , 2 , 3}>$ DPS was to develop[B] an accounting system to meet Smith's specific needs. $<\mathbf{1 , 1 , 2 , 4}>$ However[c], the defendant refused to pay[B] DPS' billing after having paid several billings submitted by DPS. $<\mathbf{1 , 1 , 2 , 5}>$ DPS [1] sued [B] Smith[3], alleging breach of the contract. $<\mathbf{1 , 1 , 2 , 6}>$ The trial court[1] held in favor of Smith [g] and DPS appealed[B].

Example (3) is the legal facts in Brief No. 07, in which the learner has used information elements to connect six information units at Level 2 coherently with each other. Among those elements, the entities 'agent [1]' and 'patient [3]' represent the parties involved in the case, i.e. the plaintiff 'DPS', the defendant 'Smith' and the Court of First Instance 'the trial court', the entity 'dative [2]' takes on the subject matter 'computer software' in the sales; the process 'behavior [B]' is quite rich, e.g. 'contracted', 'refused', 'sued', 'appealed' and so on, which can highlight all the parties' performances and avoid static information for the purpose of the vividness in writing (Du, 2009); the conditions 'time [t]' (Later), 'comitative [c]' (However) and 'goal [g]' (in favor of) have linked all the parties' behaviors to each other, aiming at the coherence in legal facts. Through the main information processing, the relations between all the parties and the progress of the case have been clearly introduced to readers, the legal facts have been constructed at the micro level and the solid foundation has been laid for the solution to the legal issue eventually.

\subsection{Discourse Information Processing in Self-assessment for Case Briefs}

Based on conceptualizations of autonomous and life-long learning, self-assessment can improve the efficiency in English learning; "equipped with self-assessment skills, students gradually develop a critical attitude toward learning throughout their lives and in the long run achieve the fullest autonomy (Chen, 2008)"; the process of self-assessment can also promote learners' self-efficacy for writing (Andrade et al., 2009). In terms of process genre approach based on the analytical framework in Figure 4, Chinese EFL learners will self-assess their brief writing through discourse information processing.

\subsubsection{Tree Information Diagram and Self-assessment for Macro Structure}

CLIPS can provide the tree information diagram of Model No. 02 as reference for self-assessment for the macro discourse structures in the learners' briefs. As for legal reasoning (see Figure 9), both the two knots ' $\angle \mathrm{WJ}>$ ' have developed to lower information, including ' $<\mathrm{WF}>$ ', ' $<\mathrm{WB}>$ ', and ' $<\mathrm{WI}>$ ' supported by ' $<\mathrm{WF}>$ '. Thus, the legal reasoning has been organized rationally, deeply and logically.

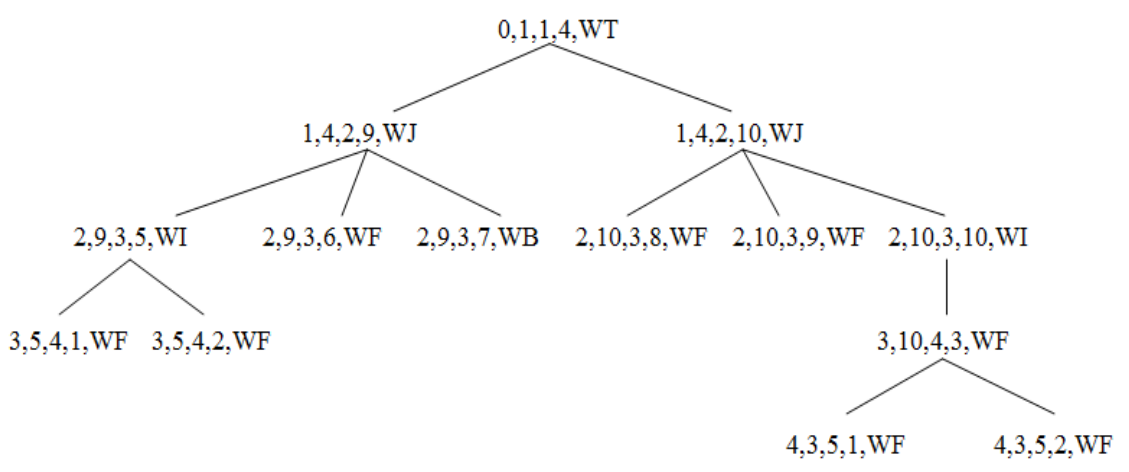

Figure 9. Information structure of reasoning in Model No. 02 
Starting from the reference to the model information structure in Figure 9, learners begin to assess their own briefs. It can be found that the legal reasoning in some of the ten briefs extracted from CLIPS needs revising before submission in that these works lack sufficient information levels and appear unclearly logical. For example, in Briefs No. 03 and 10 (see Figures 10 and 11), less importance is attached to the logical relations between information units. Instead, the WFs are just carelessly placed together. Since WFs, WIs and WJ are positioned at the same level, the reasoning result and the legal facts are not hierarchical, let alone where the relations 'WF-WI' (fact-inference) or 'WF-WJ' (fact-judgment) is constructed. Even in Brief No. 03, three subjective WIs come into being consecutively (see dotted circle in Figure 10) although there are no supportive WFs at the lower levels. The macro-structural analysis shows that the internal relations in the reasoning part of these briefs are confusing in spite of sufficient information units. Whether there are improper use of cohesive devices and lack of local coherence depend on the micro self-assessment.

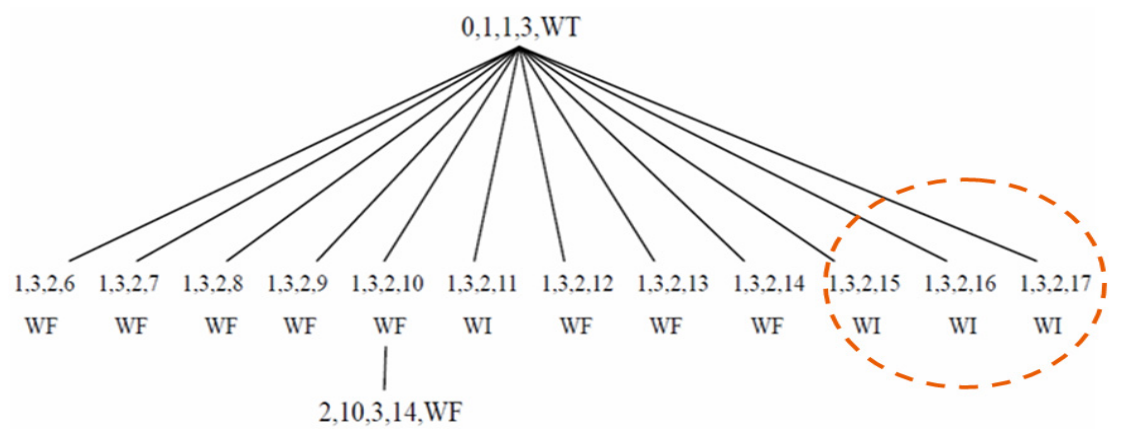

Figure 10. Information structure of partial reasoning in Brief No. 03

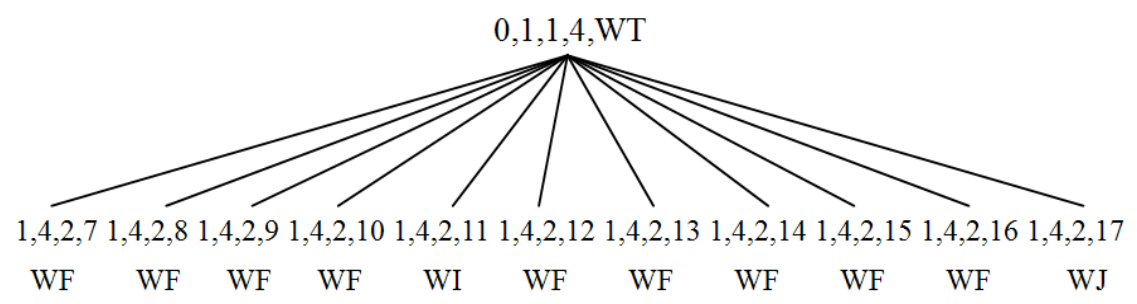

Figure 11. Information structure of partial reasoning in Brief No. 10

\subsubsection{Micro Information Processing in Self-assessment for Words, Sentences and Texts}

From the angle of information units and sentence structures, whether there is redundant information will be firstly investigated while doing the self-assessment for the works. For example,

(4) $<1,2,2,10, \mathrm{WJ}>1$. Whether the lawsuit is good or service?

$<1,2,2,11, \mathrm{WJ}>2$. Whether the UCC was applicable to these agreements?

In Example (4), the learner has raised two repetitive legal issues in Brief No. 01, totally violating the principle of conciseness in the genre of case briefs. In terms of UCC, the two issues are essentially one question raised in two different ways, so one legal issue is enough. In Brief No. 03, nearly 500 words have been used, including 360 words for legal facts (18 information units) and legal reasoning (14 information units), resulting in much redundant information in the brief.

Obviously, the information knot ' $\angle \mathrm{WF}>$ ' is one of the focuses in self-assessment in that the importance of ' $<\mathrm{WF}>$ ' in legal reasoning has been mentioned above. However, inappropriate use of or lack of cohesive devices will give rise to excessive use or misuse of ' $\angle \mathrm{WF}\rangle$ '. Consequently, the counterproductive information distribution will influence global coherence or local coherence in the whole discourse (van Dijk, 1985). For example,

(5) $<\mathbf{W F}>$ In this case, DPS sold not "hardware" to Smith. $<\mathbf{W F}>$ Instead, DPS retained to design, develop and implement an electronic data processing system to meet Smith's specific needs. $<\mathbf{W F}>$ And the transaction was intangible. $<\mathbf{W F}>$ There are some similar cases can apply to this case. $<\mathbf{W F}>\mathrm{UCC}$ do not apply. 


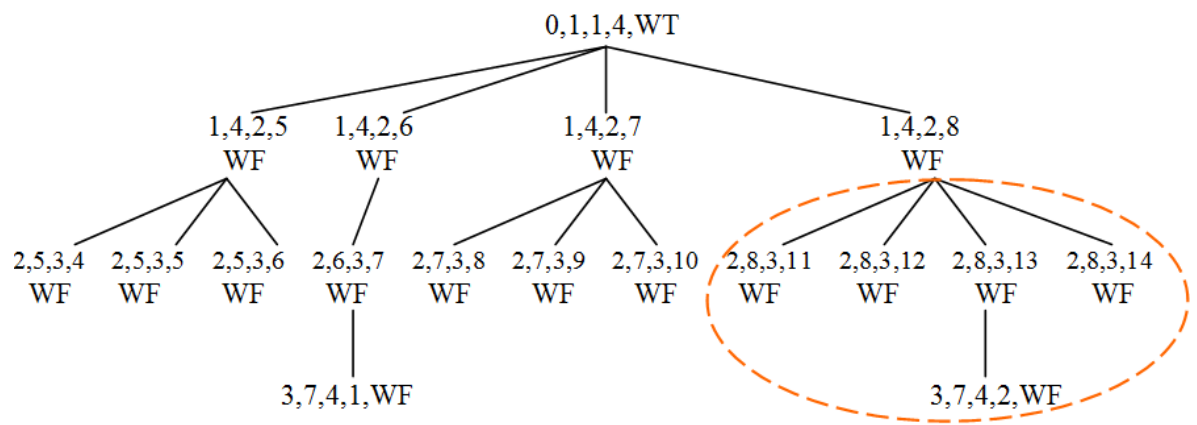

Figure 12. Information structure of partial reasoning in Brief No. 06

Example (5) contains the last few information units in legal reasoning of Brief No. 06 (see dotted circle in Figure 12), in which the five information knots are all WFs. Here no proper cohesive devices have been used, and the information knot ' $<\mathrm{WF}>$ ' has been alternatively put in the last information unit $<2,8,3,14>$, supposed to be the knot ' $<$ WI $>$ '. Thus, the hierarchical relation 'WF-WI' (fact-inference) cannot be constructed and the reasoning is illogical. Such problems affecting local coherence have also been found in Briefs No. 03 and 10 (see Figures 10 and 11) in that the lack of cohesive devices between WI or WJ and WFs leads to the superficial phenomenon that legal facts and legal inference or judgment are put at the same level, and leads to the local incoherence internally. Therefore, despite rich information provided in this part, the persuasiveness of the whole reasoning has been reduced by the unsound hierarchy.

The analysis of information elements is conducive to self-assessment for local coherence in a text. Loss of or misuse of information elements will affect information knots and local coherence, eventually leading to global incoherence in a text in that the disordered information units cannot serve the $\mathrm{KN}$ or their superordinates effectively. The reason for the local incoherence in Example (5) lies in that there are no information elements used as cohesive devices between Information Units 4 and 5. But this problem has been avoided in Brief No. 05, i.e. the information element 'comitative [c]' (Thus) has been used between the information units 'The means of transmission is not $[\mathbf{R}]$ the essence of the agreement. Thus $[\mathbf{c}]$, the provisions of the UCC do not apply.' The element 'thus' elicits the information from the foregoing element 'Relation [R]' (is not), and the information introduced by 'thus' is the rational judgment made based on the preceding reasoning. Accordingly, the proper element 'comitative [c]' helps achieve local coherence. Take the following as another example,

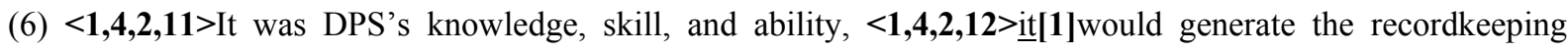
computer functions DPS was to develop.

Example (6) consists of two information units in legal reasoning of Brief No. 08, in which the paralleled units $<1,4,2,11>$ and $<1,4,2,12>$ are the 11th and 12th at Level 2 . The linguistic analysis shows that no cohesive device used between them leads to local incoherence while the discourse information analysis illustrates that the incoherence results from the loss or misuse of information elements. If one element 'comitative [c]' (although) was added before the information unit $<1,4,2,12>$ or the element 'agent [1]' (it) in the unit $<1,4,2,12>$ was changed into 'which', the hierarchical relation would be created between the two units, in which the latter would be subordinate to the former. Then local coherence would be achieved in that the two information units had been clearly and logically restructured.

\section{Discussion}

\subsection{Language Use in Case Brief Writing}

In the stage of case brief writing, learners can make full use of the resources, including legal settings, writing purposes and legal register, from CLIPS for their information input. Since case brief writing depends on effective language output (Crane, 2010), learners can refer to the model briefs, form a macro tree information structure, list key words for each part and finally write the macro outline of their own briefs. In the process, learners can start from the macro structure, control the number of information units, and avoid redundant information; write the title of their own briefs by referring to the formulaic expression 'A (plaintiff) v. B (defendant)', raise legal issues like the expression 'Whether....', and write out the court decision with the structure 'yes or no'; utilize objective and concise language to state highly-shared and well-accepted legal facts, conforming to the genre features; use highly-shared objective language to support legal inference or legal judgment for legal reasoning, advancing the development of information levels. 
Then, much importance is attached to the language use at the micro level in legal facts and legal reasoning. Concise language and logical structure of legal genres ( $\mathrm{Li}, 2008)$ can help achieve semantic coherence in language output (van Dijk, 1985). Therefore, the reasonable distribution of information knots and proper use of information elements as cohesive devices should be taken into consideration to guarantee the full use of WFs, the integration of WFs and WBs, and the subsidiary role of other knots. While transmitting the information ' $<\mathrm{WF}>$ ', action verbs should be used frequently to state objective legal facts, and linking verbs can be used to express the relations between the parties involved and to describe what has happened in the cases. In the part of legal reasoning, necessary cohesive devices should be used to convey the logical information like 'WF-WI' (fact-inference) or 'WF-WJ' (fact-judgment).

\subsection{Language Use in Self-assessment for Case Briefs}

The relevant model briefs are selected from CLIPS for the convenience of effective self-assessment for writing. Learners' self-assessment starts from the discourse information at the macro superordinate levels. The comparison can be made between tree information diagrams in the learners' briefs and the model briefs to investigate the language use and the global coherence in the whole texts. If there are such problems as lengthy texts or illogical structures, self-assessment will be made for the micro information distribution, i.e. starting from the information at lower levels, textual cohesion and local coherence will be examined in terms of the relations between language use (words, sentences and texts) and information processing (information knots and information elements).

Based on the results from self-assessment, learners' revision of case briefs can be done. If the text is too lengthy, redundant information will be deleted for the conciseness; if the text is illogical, some necessary cohesive information elements can be changed or added for the local coherence. Learners will polish their case briefs by themselves eventually in order that their effective language output can guarantee the achievement of their writing purposes conforming to the legal register features.

\section{Conclusion}

This paper designs a corpus-based information analytical framework for Chinese EFL learners' autonomy in legal case brief writing. Based on process genre approach and discourse information analysis, it explores how learners take advantage of the resources from CLIPS to obtain, transmit and assess discourse information in the process of their writing, and how learners achieve discourse information processing with language use. However, the cultivation of learners' autonomy in writing is just an attempt in the teaching practice, and it is very necessary to conduct a large-scale experimental study. So, in the near future deeper research will be made to perfect the analytical model for the improvement of learners' autonomy in writing. It is hoped that the study will help Chinese EFL learners build information awareness in legal writing and promote their language output and autonomous learning and that the research will offer a reference for the advancement of ESP teaching reform and practice.

\section{Acknowledgments}

This paper is funded by the 2016 Guangdong Provincial Research Project of Teaching Reform "An e-Portfolio-based Model for the Application, Sharing and Promotion of College English ESP MOOCs (109-XCQ16266)" and "Research Center for English Testing and Assessment" of Guangdong University of Foreign Studies.

\section{References}

Andrade, H., Wang, X., Du, Y., \& Akawi, R. (2009). Rubric-Referenced Self-Assessment and Self-Efficacy for Writing. The Journal of Educational Research, 102(4), 287-301. http://dx.doi.org/10.3200/JOER.102.4.287-302

Badger, R., \& White, G. (2000). A process genre approach to teaching writing. ELT Journal, 54(2), 153-160. https://doi.org/10.1093/elt/54.2.153

Bhatia, V. (2013). Analysing genre: language use in professional settings. New York: Routledge.

Biber, D., \& Conrad, S. (2009). Register, genre, and style. Cambridge: Cambridge University Press. https://doi.org/10.1017/CBO9780511814358

Bowles, H. (2012). Analyzing Languages for Specific Purposes Discourse. The Modern Language Journal, 96(s1), 43-58. https://doi.org/10.1111/j.1540-4781.2012.01296.x

Brumbaugh, J. (Ed.), (1917). Legal Reasoning and Logic Applied to the Preparation Trial and Appeal of with Illustrative Briefs and Forms. The Bobbs-Merrill Company Publishers. 
Candlin, C., Bhatia, V., \& Jensen, C. (2002). Developing legal writing materials for English second language learners: problems and perspectives. English for Specific Purposes, 21(4), 299-320. https://doi.org/10.1016/S0889-4906(01)00029-1

Chang, R. (2015). The Status Quo and Reflections on Legal English Teaching in Law Major. Theory and Practice of Education, 35(6), 54-55.

Chen, Y. (2008). Learning to self-assess oral performance in English: A longitudinal case study. Language Teaching Research, 12(2), 235-262. https://doi.org/10.1177/1362168807086293

Chen, J. (2015). Self-Assessment for Legal English Writing. International Journal of Legal English, 3(2), 57-69.

Clarence, S., Albertus, L., \& Mwambene, L. (2014). Building an evolving method and materials for teaching legal writing in large classes. Higher Education, 67(6), 839-851. https://doi.org/10.1007/s10734-013-9707-8

Court of Appeals of Indiana. (1986). Data Processing Services, Inc. v. L.H. Smith Oil, Corp. North Eastern Reporter, Second Series, 492, 314.

Crane, J. (2010). Legal Case Brief Workbook. The Center for Life Improvement Publishing.

$\mathrm{Du}$, J. (2007). A study of the tree information structure of legal discourse. Modern Foreign Languages (Quarterly), 30(1), 40-50.

Du, J. (2009). A Study of the Discourse Information Features in Advanced Writing by English Majors. Foreign Language Education, 30(2), $42-46$.

Du, J. (Ed.), (2013). Discourse Analysis. Wuhan: Wuhan University Press.

Du, J. (2014). On Legal Discourse Information. Beijing: People's Publishing House.

Flowerdew, J. (1993). An educational, or process, approach to the teaching of professional genres. ELT Journal, 47(4), 305-316. https://doi.org/10.1093/elt/47.4.305

Friginal, E. (2013). Developing research report writing skills using corpora. English for Specific Purposes, 32(4), 208-220. http://dx.doi.org/10.1016/j.esp.2013.06.001

Garner, B. (Ed.), (2004). Black's Law Dictionary (8th edition). St. Paul: West, a Thompson business.

Ge, Y. (2014). Resolution of conflict of interest in Chinese civil court hearings: a perspective of discourse information theory. The International Journal of Speech, Language and the Law, 21(1), 63-68. https://doi.org/10.1558/ijsll.v21i1.163

Gersten, D. (2007). Effective Brief Writing and Oral Argument: Gaining the Inside Track. Florida Bar Journal, 81(4), 26-29.

Guan, X. (2015). Potential Speaker-Discriminating Power of Speaking Style: Application of Discourse Information Analysis to Forensic Speaker Recognition. International Journal of Law, Language \& Discourse, 5(1), 38-65.

Hedge, T. (1993). Writing. Oxford: Oxford University Press.

Hong, H., \& Cao, F. (2014). Interactional metadiscourse in young EFL learner writing: A corpus-based study. International Journal of Corpus Linguistics, 19(2), 201-224. https://doi.org/10.1075/ijcl.19.2.03hon

Krois-Lindner, A., \& TransLegal (Eds.). (2006). International Legal English: A course for classroom or self-study use. Cambridge: Cambridge University Press.

Huang, Z., \& Xia, Y. (2010). Difficulties and reform in legal English teaching. China University Teaching, (4), 48-51.

LeClercq, T. (Ed.). (1995). Expert Legal Writing. Austin: University of Texas Press.

Li, K. (2008). Composing and Translating Conditional Clauses in Legal Texts. Chinese Translators Journal, (4), 71-77.

Maciel, A. M. B., Marmet, L., \& Curcio Celia, M. H. (1983). Developing a System for Specifying Objectives. Working Paper No. II. Brazalian ESP Project.

McElhaney, J. W. (1996). The art of persuasive legal writing. ABA Journal, (1), 76-78.

Miao, Q. (2014). The Predicaments and Countermeasures to Expand English for Academic Purposes Teaching in Higher Education Institutions: from the Perspective of Legal English Teaching. Foreign Language Learning 
Theory and Practice, (3), 65-70.

Moessner, L. (2001). Genre, Text Type, Style, Register: A Terminological Maze?. European Journal of English Studies, 5(2), 131-138. http://dx.doi.org/10.1076/ejes.5.2.131.7312

Pan, X., \& Du, J. (2011). Information Flow of Process Control in Courtroom Question and Response. Journal of Foreign Languages, (2), 56-63.

Pincas, A. (Ed.), (1982a). Teaching English Writing. London: Macmillan.

Pincas, A. (Ed.), (1982b). Wring in English 1. London: Macmillan.

Pyle, C., \& Killoran, K. (1999). How To Brief a Case?. http://www.lib.jjay.cuny.edu/research/brief.html.

Ren, R., \& Ding, N. (2012). "5W1H” analysis of key factors involved in ESP teaching. Foreign Language World, (2), 58-64.

van Dijk, T. (1985). Semantic Discourse Analysis. In T. A. van Dijk (Ed.), Handbook of Discourse Analysis: Dimensions of Discourse, Vol. 2 (pp. 103-112). London: Academic Press, Inc. (London) Ltd.

Wang, Q. (2003). A study of legal English teaching model based on case method. Journal of Ningbo University (Educational Science), 25(5), 111-112; 139.

Wang, Q., \& Zhao, G. (2009). An Overview on Case Method Researches at Home and Abroad. Journal of Ningbo University (Educational Edition), 31(3), 7-11.

Wen, Q. (2008). Output-driven Hypothesis and the Reform of English-skill Curriculum for English Majors in China. Foreign Language World, (2), 2-9.

Wen, Q. (2013). The Application of Output-driven Hypothesis in College English Teaching Practice: Thoughts and Suggestions. Foreign Language World, (6), 14-22.

White, R., \& Arndt, V. (1991). Process Writing. Harlow: Longman.

Wu, Y. (2010). The application of case method in economic law teaching. Education Exploration, (5), 80-81.

\section{Copyrights}

Copyright for this article is retained by the author(s), with first publication rights granted to the journal.

This is an open-access article distributed under the terms and conditions of the Creative Commons Attribution license (http://creativecommons.org/licenses/by/4.0/). 